\title{
EFEITO DA ESPERMINA NA QUALIDADE FISIOLÓGICA DE SEMENTES DE ALFACE ${ }^{1}$
}

\author{
SANDRA MULLER GARCIA²; DARIO MUNT DE MORAES ${ }^{3}$
}

RESUMO - O objetivo nesse estudo foi investigar o desempenho dos reguladores do crescimento: ácido giberélico, espermina e ácido abscísico na germinação e no crescimento inicial de plântulas de alface cv. Grand Rapids. Para isso, as sementes foram tratadas com soluções de ácido giberélico, espermina, e ácido abscísico na concentração de $0,5 \mathrm{mM} ; 0,05 \mathrm{mM}$ e $0,04 \mathrm{mM}$ respectivamente e avaliadas por meio dos testes de germinação, primeira contagem da germinação, emergência de plântulas, índice de velocidade de emergência de plântulas, comprimento de parte aérea e raiz das plântulas, massas fresca e seca total de plântulas, teste de condutividade elétrica e atividade total da enzima da $\alpha$ - amilase. A espermina aplicada isoladamente embora tenha induzido aumento da atividade da enzima $\alpha$-amilase teve pouco efeito na indução da germinação de sementes de alface, sendo que reduziu de maneira geral a viabilidade e vigor das sementes. No entanto, quando foi combinada com o ácido giberélico ou abscísico induziu o crescimento da parte aérea superando quando presente a ação inibitória do ácido abscísico. O ácido abscísico apresenta efeito positivo na reorganização de membranas. Com base nos resultados, pode-se inferir que os fitorreguladores não afetam a viabilidade das sementes e que sementes tratadas com espermina apresentam pior desempenho no vigor.

Termos para indexação: reguladores de crescimento, qualidade fisiológica, vigor.

\section{EFFECT OF SPERMINE ON THE PHYSIOLOGICAL QUALITY OF LETTUCE SEEDS}

\begin{abstract}
The objective of this study was to investigate the performance of the growth regulators: gibberellic acid, spermine and abscisic acid, on the germination and early growth of seedlings of the lettuce cv. Grand Rapids. The experiments were conducted in the greenhouse and laboratory and the seeds treated with solutions of gibberellic acid, spermine and abscisic acid at concentrations of $0.5 \mathrm{mM}, 0.05 \mathrm{mM}$ and $0.04 \mathrm{mM}$ respectively. Tests for germination, first count of germination, emergence, emergence speed index, shoot and root lengths, fresh and dry seedling weights, electrical conductivity and $\alpha$-amylase activity were conducted. Although the spermine applied by itself induced increased $\alpha$-amylase activity, it had little effect on inducing germination in lettuce and generally reduced seed viability and vigor. However, when combined with gibberellic or abscisic acids it induced shoot growth and overcame the inhibitory action of abscisic acid. Abscisic acid had a positive effect on membrane reorganization. It can be inferred from the results that the growth regulators did not affect lettuce seed viability and that the performance of seeds treated with spermine was worse.
\end{abstract}

Index terms: growth regulators, physiological quality, vigor.

\footnotetext{
${ }^{1}$ Submetido em 11/09/10. Aceito para publicação em 31/03/11. Parte da Dissertação de Mestrado do primeiro autor apresentada a UFPEL (Universidade Federal de Pelotas).

${ }^{2}$ Eng. Agr, Mestre em Ciência e Tecnologia de Sementes, UFPEL, sandra.
}

mullergarcia@gmail.com ${ }^{3}$ Eng. Agr., Dr., Professor Titular, Departamento de Botânica, UFPEL,
Caixa postal, $354,96010-900$, Pelotas-RS, Brasil., moraesdm@ufpel.
edu.br 


\section{INTRODUÇÃO}

Os eventos fisiológicos de crescimento e desenvolvimento que ocorrem nos vegetais representam um processo integrado, complexo e pouco conhecido, havendo, entretanto, uma estreita relação desses eventos com a ação de substâncias conhecidas como fitohormônios.

Entre os novos reguladores de crescimento encontramse as poliaminas biogénicas putrescina, espermidina e espermina envolvidas em processos celulares e sub celulares. São importantes moduladores de processos biológicos como na divisão celular, em respostas ao estresse e do desenvolvimento (Koetje et al., 1993).

As poliaminas estão presentes em inúmeras etapas do crescimento e diferenciação das plantas, como a germinação, divisão celular, diferenciação das folhas, flores e raízes, senescência de órgãos e outros (Galston e Kaur-Sawhney, 1995).

Com respeito ao mecanismo de ação, as poliaminas podem interagir com membranas celulares, eliminar radicais livres e alterar a expressão gênica (Matilla, 1996). O conteúdo e a concentração de poliaminas, em sementes maduras, variam de acordo com a espécie, havendo uma distribuição entre os órgãos de reserva (cotilédones e endosperma) e eixo embrionário.
A relação das poliaminas com outros reguladores de crescimento ainda não são completamente conhecidas, embora estudos conduzidos relacionando poliaminas e outros reguladores tenham mostrado correlação entre o aumento do conteúdo destas com o aumento dos outros fito hormônios (Gemici et. al., 2006). Assim sendo, no presente trabalho teve-se por objetivo investigar o efeito da poliamina espermina e sua relação com os reguladores do crescimento ácido giberélico e abscísico sobre a qualidade fisiológica da semente e crescimento das plântulas de alface cv. Grand Rapids.

\section{MATERIAL E MÉTODOS}

O experimento foi conduzido no Laboratório de Análises de sementes da Faculdade de Agronomia Eliseu Maciel, no Laboratório do Departamento de Botânica do Instituto de Biologia e em Casa de Vegetação do Departamento de Solos, da Universidade Federal de Pelotas. Sementes de alface da cv. Grand Rapids com $97 \%$ de germinação foram submetidas à soluções de ácido giberélico $\left(\mathrm{AG}_{3}\right)$, espermina (Esp) e ácido abscísico (ABA) nas concentrações de $0,5 \mathrm{mM} ; 0,05 \mathrm{mM}$ e $0,04 \mathrm{mM}$ respectivamente e das combinações desses reguladores de crescimento conforme (Tabela 1).

TABELA 1. Soluções de reguladores de crescimento e suas associações. Presença do regulador do crescimento (+) e ausência (-).

\begin{tabular}{lccc}
\hline \multirow{2}{*}{ Tratamentos } & \multicolumn{3}{c}{ Reguladores do Crescimento } \\
\cline { 2 - 4 } Controle & $\mathrm{AG}_{3}(0,5 \mathrm{mM})$ & $\mathrm{Esp}(0,05 \mathrm{mM})$ & $\mathrm{ABA}(0,04 \mathrm{mM})$ \\
$\mathrm{AG}_{3}+$ Esp +ABA & - & - & - \\
$\mathrm{AG}_{3}+$ Esp & + & + & + \\
$\mathrm{AG}_{3}+\mathrm{ABA}$ & + & + & - \\
$\mathrm{AG}_{3}$ & + & - & + \\
$\mathrm{ABA}$ & + & - & + \\
Esp & - & + & - \\
Esp + ABA & - & + & + \\
\hline
\end{tabular}

Para a avaliação do efeito da espermina isolada ou em associação com o ácido giberélico e ácido abscísico sobre a qualidade fisiológica das sementes de alface foram utilizados os seguintes testes:

- Germinação (TG) e primeira contagem de germinação - foram semeadas 50 sementes em cada gerbox totalizando 200 sementes por repetição, sendo utilizado como substrato papel mata borrão previamente umedecido com $15 \mathrm{~mL}$ de cada solução teste ou água destilada para o tratamento controle. Após a semeadura os gerbox foram colocados em câmara BOD na temperatura de $20^{\circ} \mathrm{C}$. Foram realizadas avaliações pelos critérios das Regras de Análises de Sementes (Brasil, 2009), aos quatro dias e sete dias após a semeadura.

- Emergência de plântulas em casa-de-vegetação - foram utilizadas no total 4800 sementes divididas em 
três repetições de 200 sementes em cada tratamento, previamente embebidas nas soluções teste, por uma hora. As sementes foram semeadas em bandejas, em casa de vegetação, sendo utilizado substrato plantmax. Vinte e um dias após a semeadura foram observados e anotados o número de plântulas emergidas.

- Velocidade de emergência - foi utilizado o mesmo ensaio do teste de emergência de plântulas. A partir da emergência da primeira plântula, foram feitas observações diárias, contando-se o número de plântulas até que este permanecesse constante. O resultado foi expresso, em gráfico, pelo número acumulado de sementes germinadas por dia, ao longo do período de observação.

- Comprimento da parte aérea e do sistema radicular das plântulas - quarenta plântulas normais retiradas aleatoriamente de cada repetição estatística do teste de germinação (7dias) e teste de emergência de plântulas em casa-de-vegetação (21 dias), foram retiradas do substrato e medidas à parte aérea e raiz com o auxílio de uma régua.

- Massa da matéria fresca e seca total das plântulas - quarenta plântulas normais foram retiradas aleatoriamente de cada repetição estatística do teste de germinação (7dias) e emergência de plântulas em casa-de-vegetação (21 dias), realizando-se a pesagem delas para obter a biomassa fresca. A seguir, foram colocadas em sacos de papel separados por repetição, por tratamento posto para secar em estufa $70{ }^{\circ} \mathrm{C}$ durante $24 \mathrm{~h}$. Após esse período as amostras foram retiradas da estufa e colocadas para esfriar em dessecador, pesadas em balança e determinando à massa da matéria seca.

- Condutividade elétrica (CE) - foram utilizadas três repetições de quatro subamostras de 50 sementes, por tratamento. Cada subamostra foi pesada e colocada por uma hora nos tratamentos com ácido abscísico, ácido giberélico e espermina, após esse período as sementes foram enxaguadas em água destilada e colocadas para embeber em um recipiente contendo $25 \mathrm{~mL}$ de água deionizada, sendo mantidas em um ambiente à temperatura de $20^{\circ} \mathrm{C}$. Foram realizadas leituras as duas, quatro e seis horas após a embebição em água deionizada.

- Atividade total da enzima $\alpha$-amilase - para a determinação da atividade enzimática as extrações foram feitas nos tempos zero (semente); aos quatro dias e aos sete dias após semeadura. Foram utilizadas quatro repetições de $0,5 \mathrm{~g}$ de sementes (tempo zero) e quatro repetições de 0,5 $\mathrm{g}$ de plântulas (aos cinco e sete dias). As sementes foram tratadas com os hormônios por uma hora e as plântulas foram obtidas de um substrato umedecido com as soluções. As leituras foram realizadas em espectrofotômetro E -
225D a $620 \mathrm{~nm}$ (AOSA, 1983). Os dados das leituras foram transformados pela seguinte fórmula:

A.T. $=[($ substrato a $620 \mathrm{~nm}$ - leitura $620 \mathrm{~nm}) / 5 . \mathrm{x})] .(20 /$ 0,5. $0,5 \mathrm{~g}$ ), onde $\mathrm{x}=1 \mu \mathrm{g}$ de amido.

\section{RESULTADOS E DISCUSSÃO}

$\mathrm{Na}$ avaliação da primeira contagem da germinação (PCG\%) das sementes de alface cv. Grand Rapids (Tabela 2) expostas aos diferentes tratamentos observa-se o único que diferiu estatisticamente foi à com ABA isoladamente, o qual induziu decréscimo em comparação ao controle. Para a germinação a associação entre espermina, ácido giberélico e ácido abscísico não ocasionaram alterações na germinação das sementes de alface cv. Grand Rapids quando comparadas à aplicação isolada destas substâncias e ao controle. Os resultados obtidos para a porcentagem de germinação são diferentes dos encontrados por Sinska e Lewandoska (1991) que constataram que a aplicação de espermina inibiu o processo de germinação das sementes de maça (Malus domestica). Em outro trabalho, a aplicação de espermina diminuiu a inibição da germinação de sementes de Lotus japonicus provocada pela adição de glicose, e estimulou a germinação das sementes na ausência do sacarídeo (Zhao et. al., 2009).

Os resultados médios da velocidade de emergência das plântulas normais evidenciaram que os menores valores foram obtidos com as sementes tratadas com espermina (Figura 1). Para a emergência final das plântulas em casa de vegetação o tratamento com espermina também foi inferior aos demais tratamentos (Tabela 2). No entanto, em trabalho desenvolvido por Gemici et. al. (2006), a aplicação do precursor das poliaminas diminuiu o tempo de germinação estimulando o processo em sementes de Capsicum annuит $\mathrm{L}$.

Em vários estudos foi demonstrado que o $\mathrm{ABA}$ possui papel preventivo na germinação precoce de sementes, sendo que, altos níveis de ABA aumentam a sensibilidade da semente diminuindo o potencial hídrico e conseqüentemente reduzindo a capacidade de germinação (Arteca, 1996). Em trabalho desenvolvido por Garciarrubio et al. (1997), a adição de ABA em sementes não-dormentes de Arabidopsis inibiu a germinação. Estes autores sugeriram que essas sementes não germinaram devido ao ABA impedir a degradação de proteínas de reserva nas sementes, restringindo assim, a disponibilidade de energia e metabólitos. Em sementes de alfafa a aplicação de ABA retardou a germinação das sementes, porém não impediu a ocorrência do processo (Carneiro et al., 2001). 
TABELA 2. Primeira contagem de germinação ( $1^{a}$ PG\%), porcentagem de germinação (G\%) e emergência de plântulas em casa de vegetação (E\%) de sementes de alface cv. Grand Rapids submetidas a diferentes tratamentos com ácido giberélico $(0,5 \mathrm{mM})$, espermina $(0,05 \mathrm{mM})$ e ácido abscísico $(0,04 \mathrm{mM})$.

\begin{tabular}{lccc}
\hline \multicolumn{1}{c}{ Tratamentos } & $1^{\mathrm{a}} \mathrm{PG} \mathrm{G}(\%)$ & $\mathrm{G}(\%)$ & $\mathrm{E}(\%)$ \\
\hline Controle & $97 \mathrm{a}$ & $97 \mathrm{a}$ & $97 \mathrm{a}$ \\
$\mathrm{AG}_{3}+$ Esp +ABA & $93 \mathrm{ab}$ & $94 \mathrm{a}$ & $92 \mathrm{ab}$ \\
$\mathrm{AG}_{3}+\mathrm{Esp}$ & $96 \mathrm{ab}$ & $96 \mathrm{a}$ & $88 \mathrm{ab}$ \\
$\mathrm{AG}_{3}+\mathrm{ABA}$ & $94 \mathrm{ab}$ & $96 \mathrm{a}$ & $95 \mathrm{ab}$ \\
$\mathrm{AG}_{3}$ & $97 \mathrm{a}$ & $97 \mathrm{a}$ & $97 \mathrm{a}$ \\
$\mathrm{ABA}$ & $89 \mathrm{~b}$ & $92 \mathrm{a}$ & $92 \mathrm{ab}$ \\
$\mathrm{Esp}$ & $96 \mathrm{a}$ & $97 \mathrm{a}$ & $85 \mathrm{~b}$ \\
$\mathrm{Esp}+\mathrm{ABA}$ & $92 \mathrm{ab}$ & $94 \mathrm{a}$ & $93 \mathrm{ab}$ \\
\hline $\mathrm{CV}$ & 3,09 & 2,65 & 4,05 \\
\hline
\end{tabular}

* Médias seguidas por mesma letra, na coluna, não diferem entre si pelo teste de Tukey ao nível de $5 \%$ de probabilidade

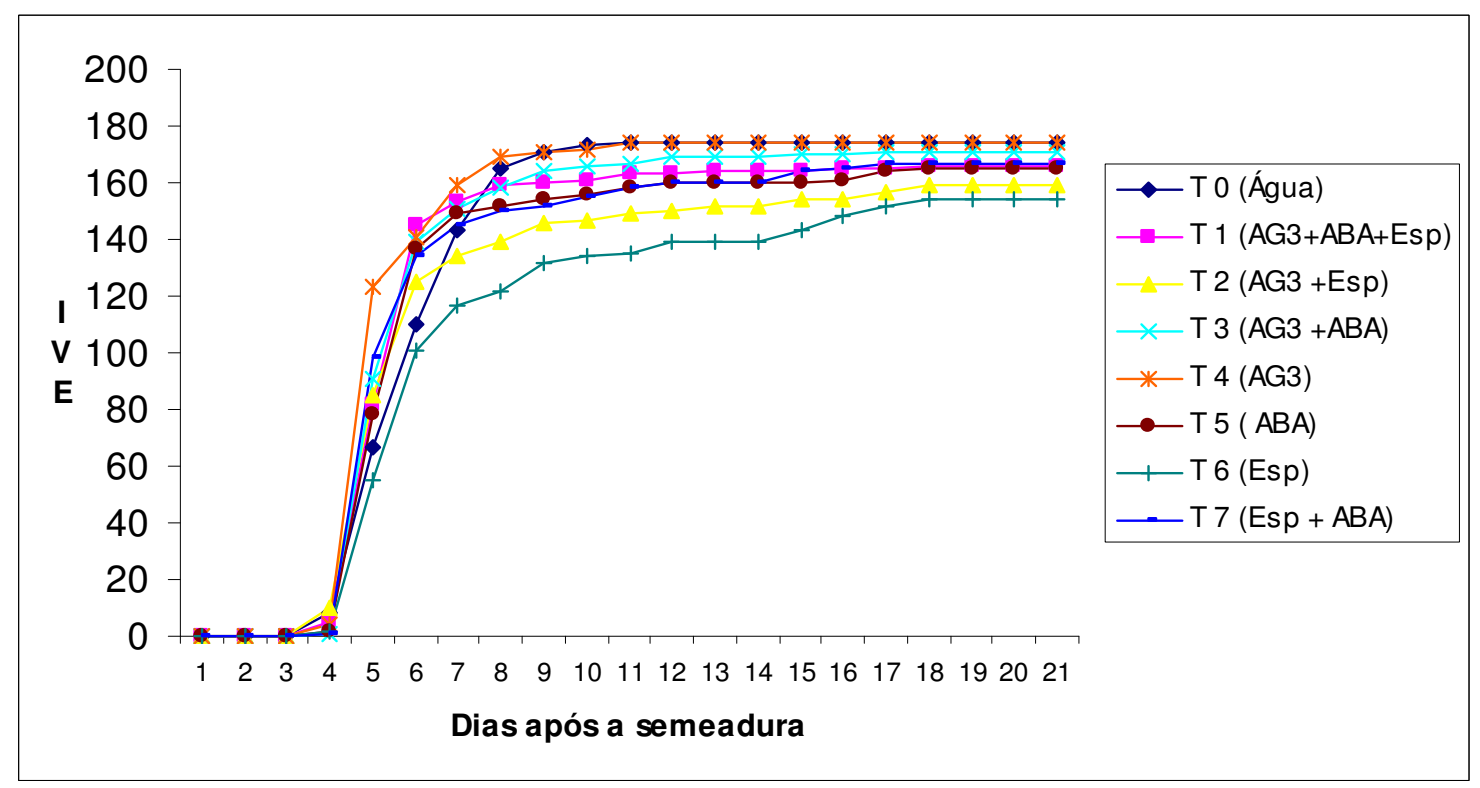

FIGURA 1. Índice de velocidade de emergência de plântulas em casa de vegetação (IVE) de sementes de alface cv. Grand Rapids expostas aos diferentes tratamentos com os reguladores de crescimento ácido giberélico $\left(\mathrm{AG}_{3}\right)$, espermina (Esp) e ácido abscísico (ABA).

Pelos resultados da emergência das plântulas em casa de vegetação (E\%), observou-se uma tendência a decrescer para todos os tratamentos, exceto para $\mathrm{o}_{\mathrm{AG}_{3}}$ que manteve a mesma porcentagem de emergência das plântulas que $o$ controle (Tabela 2). Esse resultado confirma o papel das giberelinas na contribuição do processo de germinação por meio da ativação do crescimento do embrião, mobilização de reservas energéticas e enfraquecimento da camada do endosperma (Taiz e Zeiger, 2004). Em outro trabalho desenvolvido com sementes de alface, que foram colocadas para germinar em condições de escuro a $20{ }^{\circ} \mathrm{C}$, o ácido giberélico $\left(\mathrm{AG}_{3}\right)$ estimulou a germinação das mesmas, 
quando submetidas a concentrações de 25; 50; 100 e 200 $\mathrm{mgL}^{-1}$ (Cunha e Casali, 1989 apud Aragão et al., 2003). $\mathrm{O}$ mesmo aconteceu em sementes de milho pré-embebidas em solução de $50 \mathrm{mgL}^{-1}$ de ácido giberélico que levou a sua maior atividade metabólica, germinação e vigor (Aragão et al., 2003).

O comprimento da parte aérea das plântulas ao final do teste de germinação foi superior às médias obtidas para o controle, quando as sementes de alface foram submetidas à aplicação de todos os tratamentos com $\mathrm{AG}_{3}$ exceto a combinação $\mathrm{ABA}+\mathrm{AG}_{3}$ (Tabela 3 ). Em casa de vegetação o comprimento da parte aérea foi maior que o do controle somente para o tratamento $\mathrm{AG}_{3}+$ Esp (Tabela 3). Esses resultados estão de acordo com as observações de Salisbury e Ross (1991), que afirmaram que o $\mathrm{AG}_{3}$ exerce influência no alongamento celular de caules da maioria das espécies. Em trabalho desenvolvido com cultivares de alface Mimosa e Regina onde foi aplicado $\mathrm{AG}_{3}$ associado ao condicionamento osmótico os resultados mostraram acréscimos no comprimento da parte aérea das plântulas (Menezes et al., 2006). Galston e Kaur Sawhney (1995), relatam que a espermina, assim como as demais poliaminas, é requerida para o crescimento e desenvolvimento ótimo de várias plantas.

TABELA 3. Comprimento da parte aérea (CPA) e da raiz (CR) em mm de plântulas provenientes de sementes de alface cv. Grand Rapids submetidas a diferentes tratamentos com ácido giberélico $(0,5 \mathrm{mM})$, espermina $(0,05 \mathrm{mM})$ e ácido abscísico $(0,04 \mathrm{mM})$ em condições de laboratório (final do teste de germinação) e em casa de vegetação (final do teste de emergência de plântulas).

\begin{tabular}{lllll}
\hline \multirow{2}{*}{ Tratamentos } & \multicolumn{2}{c}{ Laboratório } & \multicolumn{2}{c}{ Casa de Vegetação } \\
\cline { 2 - 5 } Controle & CPA $(\mathrm{mm})$ & CR $(\mathrm{mm})$ & CPA $(\mathrm{mm})$ & CR $(\mathrm{mm})$ \\
$\mathrm{AG}_{3}+$ Esp +ABA & $15 \mathrm{~b}$ & $49 \mathrm{a}$ & $40 \mathrm{bc}$ & $85 \mathrm{a}$ \\
$\mathrm{AG}_{3}+$ Esp & $35 \mathrm{a}$ & $14 \mathrm{~d}$ & $44 \mathrm{abc}$ & $73 \mathrm{a}$ \\
$\mathrm{AG}_{3}+\mathrm{ABA}$ & $32 \mathrm{a}$ & $19 \mathrm{~cd}$ & $51^{\mathrm{a}}$ & $83 \mathrm{a}$ \\
$\mathrm{AG}_{3}$ & $13 \mathrm{~b}$ & $14 \mathrm{~d}$ & $35 \mathrm{c}$ & $123 \mathrm{a}$ \\
$\mathrm{ABA}$ & $35 \mathrm{a}$ & $35 \mathrm{~b}$ & $48 \mathrm{ab}$ & $60 \mathrm{a}$ \\
Esp & $16 \mathrm{~b}$ & $32 \mathrm{bc}$ & $40 \mathrm{bc}$ & $78 \mathrm{a}$ \\
Esp + ABA & $16 \mathrm{~b}$ & $23 \mathrm{bcd}$ & $36 \mathrm{c}$ & $83 \mathrm{a}$ \\
$\mathrm{CV}$ & $16 \mathrm{~b}$ & $19 \mathrm{~cd}$ & $47 \mathrm{ab}$ & $71 \mathrm{a}$ \\
\hline
\end{tabular}

* Médias seguidas por mesma letra, na coluna, não diferem entre si pelo teste de Tukey em nível de 5\% de probabilidade

Já o ABA é conhecido pelo seu efeito inibidor no crescimento das plantas, sendo este responsável pela dormência das gemas do caule, pelo bloqueio do crescimento das plantas no inverno e pelo fenômeno de dormência das sementes (Taiz e Zeiger, 2004). Porém, quando aplicado junto à Esp promoveu indução no crescimento, sugerindo que a Esp em combinação com outros reguladores estimula a divisão ou alongamento celular revertendo a ação do ABA. Resultados obtidos por Gemici et al., (2006) demonstram que a aplicação do precursor das poliaminas promove o desenvolvimento de plântulas de Capsicum annuum L., sendo esse efeito intensificado quando aplicado juntamente com a cinetina e NAA (Ácido Naftaleno-Acético).

Segundo Taiz e Zeiger (2004) as giberelinas em geral possuem pouco efeito no crescimento do sistema radicular.
Já Zeevart e Creelman (1988) discutem o efeito contraditório de ABA sobre a raiz, podendo tanto inibir quanto estimular seu crescimento. Mulkey et al., (1983) observaram que a concentração de ABA, no intervalo de 0,01 a $1 \mathrm{mM}$, apresentou efeito estimulatório, de duração aproximada de 12 horas, no crescimento da raiz, seguido de um período de inibição, e, após 24 horas, de um período de estímulo. Medições de comprimento de radícula de plântulas de angico vermelho tratado com $\mathrm{ABA}$ mostraram comprimento médio superior ao do controle (Borges et al., 1990).

A espermina aplicada isoladamente ou em conjunto com os demais reguladores reduziu o comprimento radicular em laboratório quando comparada ao tratamento controle (Tabela 3). Sendo que a combinação dos três reguladores foi o tratamento que obteve menor desenvolvimento radicular (14 mm). Dessa 
forma, quando aplicada exogenamente a Esp tem efeito negativo para o crescimento radicular da cultivar Grand Rapids independente da sua combinação com outros reguladores.

Para a massa da matéria fresca total das plântulas obtida ao final do teste de germinação (Tabela 4), verificase que a Esp não tem efeito e que apenas o tratamento com $\mathrm{AG}_{3}$ diferiu da testemunha, sendo que os demais tratamentos não diferiram entre si e a testemunha. Esses resultados para $\mathrm{o}_{3}$ estão de acordo com o encontrado em sementes de milho superdoce tratadas com $\mathrm{AG}_{3}(100$ $\mathrm{mg} \mathrm{L-}{ }^{1}$ ) onde foi observado aumento na massa de matéria fresca da parte aérea em relação ao controle (Aragão et al.,
2001). Moraes e Lopes (1998), também verificaram que a aplicação de $\mathrm{AG}_{3}$ proporcionou aumentos de massa de matéria fresca e seca de plântulas de coentro. Já, a massa da matéria seca total não mostrou diferença estatística entre os tratamentos utilizados em laboratório (final do teste de germinação) e em casa de vegetação (final do teste de emergência) (Tabela 4).

A condutividade elétrica da solução controle e da somente com $\mathrm{ABA}$, foram os únicos tratamentos em que se observaram as menores lixiviações de solutos e consequentemente maior velocidade de reorganização das membranas celulares em todas as leituras (Tabela 5).

TABELA 4. Massa da matéria fresca (MF) e (MS) seca de plântulas $\left(\mathrm{mg} \mathrm{pl}^{-1}\right)$ provenientes de sementes de alface cv. Grand Rapids submetidas a diferentes tratamentos com ácido giberélico $(0,5 \mathrm{mM})$, espermina $(0,05$ $\mathrm{mM})$ e ácido abscísico $(0,04 \mathrm{mM})$ em condições de laboratório (final do teste de germinação) e em casa de vegetação (final do teste de emergência de plântulas).

\begin{tabular}{|c|c|c|c|c|}
\hline \multirow{2}{*}{ Tratamentos } & \multicolumn{2}{|c|}{ Laboratório } & \multicolumn{2}{|c|}{ Casa de Vegetação } \\
\hline & $\mathrm{MF}\left(\mathrm{mg} \mathrm{pl}^{-1}\right)$ & $\mathrm{MS}\left(\mathrm{mg} \mathrm{pl}^{-1}\right)$ & $\mathrm{MF}\left(\mathrm{mg} \mathrm{pl}^{-1}\right)$ & $\mathrm{MS}\left(\mathrm{mg} \mathrm{pl}^{-1}\right)$ \\
\hline Controle & $109 \mathrm{bc}$ & $7 \mathrm{a}$ & $4900 \mathrm{a}$ & $490 \mathrm{a}$ \\
\hline $\mathrm{AG}_{3}+\mathrm{Esp}+\mathrm{ABA}$ & $122 b$ & $8 a$ & $3800 \mathrm{a}$ & $410 \mathrm{a}$ \\
\hline $\mathrm{AG}_{3}+\mathrm{Esp}$ & $111 \mathrm{bc}$ & $7 \mathrm{a}$ & $4300 \mathrm{a}$ & $370 \mathrm{a}$ \\
\hline $\mathrm{AG}_{3}+\mathrm{ABA}$ & $79 \mathrm{c}$ & $6 a$ & $4900 \mathrm{a}$ & $410 \mathrm{a}$ \\
\hline $\mathrm{AG}_{3}$ & $151 \mathrm{a}$ & $8 a$ & $4600 \mathrm{a}$ & $360 \mathrm{a}$ \\
\hline $\mathrm{ABA}$ & $92 \mathrm{bc}$ & $7 \mathrm{a}$ & $4800 \mathrm{a}$ & $450 \mathrm{a}$ \\
\hline Esp & $107 \mathrm{bc}$ & $8 a$ & $3900 \mathrm{a}$ & $370 \mathrm{a}$ \\
\hline $\mathrm{Esp}+\mathrm{ABA}$ & $116 b c$ & $6 a$ & $5200 \mathrm{a}$ & $510 \mathrm{a}$ \\
\hline $\mathrm{CV}$ & 15,05 & 27,21 & 12 & 19,58 \\
\hline
\end{tabular}

* Médias seguidas por mesma letra, na coluna, não diferem entre si pelo teste de Tukey ao nível de $5 \%$ de probabilidade

TABELA 5. Condutividade elétrica ( $\mu \mathrm{S} . \mathrm{cm}^{-1}$. g-1 de semente) de sementes de alface cv. Grand Rapids submetidas a diferentes tratamentos com ácido giberélico $(0,5 \mathrm{mM})$, espermina $(0,05 \mathrm{mM})$ e ácido abscísico $(0,04 \mathrm{mM})$.

\begin{tabular}{lccc}
\hline \multirow{2}{*}{ Tratamentos } & \multicolumn{3}{c}{ Condutividade Elétrica $\left(\mu \mathrm{S} . \mathrm{cm}^{-1} \cdot \mathrm{g}^{-1}\right.$ de sementes $)$} \\
\cline { 2 - 4 } Controle & $2 \mathrm{~h}$ & $4 \mathrm{~h}$ & $6 \mathrm{~h}$ \\
$\mathrm{AG}_{3}+$ Esp +ABA & $187,10 \mathrm{~b}$ & $199,83 \mathrm{c}$ & $206,36 \mathrm{~b}$ \\
$\mathrm{AG}_{3}+$ Esp & $287,60 \mathrm{ab}$ & $305,5 \mathrm{abc}$ & $312,83 \mathrm{ab}$ \\
$\mathrm{AG}_{3}+\mathrm{ABA}$ & $365,11 \mathrm{a}$ & $395,83 \mathrm{a}$ & $400,47 \mathrm{a}$ \\
$\mathrm{AG}_{3}$ & $340,96 \mathrm{a}$ & $369,89 \mathrm{ab}$ & $378,5 \mathrm{a}$ \\
$\mathrm{ABA}$ & $313,46 \mathrm{ab}$ & $324,76 \mathrm{abc}$ & $351,19 \mathrm{a}$ \\
Esp & $201,87 \mathrm{~b}$ & $210,46 \mathrm{c}$ & $217,30 \mathrm{~b}$ \\
Esp + ABA & $343,45 \mathrm{a}$ & $367,02 \mathrm{ab}$ & $381,07 \mathrm{a}$ \\
$\mathrm{CV}$ & $247,45 \mathrm{ab}$ & $266,24 \mathrm{bc}$ & $275,77 \mathrm{ab}$ \\
\hline
\end{tabular}

* Médias seguidas por mesma letra, na coluna, não diferem entre si pelo teste de Tukey ao nível de 5\% de probabilidade 
A presença de Esp ou $\mathrm{AG}_{3}$ aumentou a lixiviação de solutos em $6 \mathrm{~h}$, sendo que na presença do ABA a lixiviação de solutos foi parcialmente revertida (Tabela 5). Esse resultado contradiz os encontrados por Timm et.al. (2008) em que sementes de um dos lotes de aveia preta submetidas a concentrações de 0; 50;100 e $150 \mathrm{mgL}^{-}$ ${ }^{1}$ de $\mathrm{AG}_{3}$ tiveram diminuição na quantidade de lixiviados com o aumento da concentração de ácido giberélico, mostrando o efeito positivo da giberelina na velocidade de reorganização das membranas celulares.

A atividade total da enzima $\alpha$-amilase (Tabela 6), apresentou uma desempenho padrão da atividade da enzima para todos os tratamentos, ou seja, atividade menor na semente (zero dias), maior atividade após ativação do processo germinativo (quatro dias após a germinação) e posterior redução da atividade aos sete dias após a germinação. A Esp e Esp+ABA, foram os reguladores que mostraram menor indução na atividade da enzima $\alpha$-amilase no tempo zero (semente), no entanto, foram os que induziram maior atividade aos quatro dias após a germinação. Todos os tratamentos nos quatro dias após a germinação tiveram médias superiores ao controle o que indica que a presença dos reguladores favoreceu a atividade da $\alpha$-amilase.

TABELA 6. Atividade total da enzima alfa amilase ( $\mu \mathrm{g}$ de amido hidrolizado $\mathrm{min}^{-1} \mathrm{~g} \mathrm{de} \mathrm{sem}^{-1}$ ) para os diferentes tratamentos com ácido giberélico $\left(\mathrm{AG}_{3}\right)$, espermina (Esp) e ácido abscísico $(\mathrm{ABA})$ nos estádios de semente e 4 e 7 dias após a germinação.

\begin{tabular}{lccc}
\hline \multirow{2}{*}{ Tratamentos } & \multicolumn{3}{c}{ Atividade $\alpha$-amilase $\left(\mu \mathrm{g}\right.$ de amido hidrolizado $\left.\min ^{-1} \mathrm{~g} \mathrm{de} \mathrm{sem.}^{-1}\right)}$. \\
\cline { 2 - 4 } Controle & Semente & $4^{\mathrm{o}} \mathrm{dia}$ & $13,44 \mathrm{c}$ \\
$\mathrm{AG}_{3}+$ Esp +ABA & $8,39 \mathrm{~b}$ & $21,28 \mathrm{~d}$ & $13,36 \mathrm{c}$ \\
$\mathrm{AG}_{3}+$ Esp & $6,20 \mathrm{c}$ & $24,32 \mathrm{c}$ & $14,78 \mathrm{a}$ \\
$\mathrm{AG}_{3}+\mathrm{ABA}$ & $6,08 \mathrm{c}$ & $25,58 \mathrm{~b}$ & $13,99 \mathrm{~b}$ \\
$\mathrm{AG}_{3}$ & $11,46 \mathrm{a}$ & $25,98 \mathrm{~b}$ & $15,07 \mathrm{a}$ \\
$\mathrm{ABA}$ & $3,55 \mathrm{~d}$ & $23,85 \mathrm{c}$ & $14,7 \mathrm{a}$ \\
Esp & $4,78 \mathrm{c}$ & $24,26 \mathrm{c}$ & $14,3 \mathrm{~b}$ \\
Esp + ABA & $2,41 \mathrm{~d}$ & $29,86 \mathrm{a}$ & $13,98 \mathrm{~b}$ \\
\hline $\mathrm{CV}$ & $2,08 \mathrm{~d}$ & $28,98 \mathrm{a}$ & 3,0 \\
\hline
\end{tabular}

* Médias seguidas por mesma letra, na coluna, não diferem entre si pelo teste de Scott Knott ao nível de 5\% de probabilidade.

Aos sete dias após a germinação todos os tratamentos exceto a combinação dos três reguladores diferiram estatisticamente do controle apresentando maior atividade enzimática (Tabela 6). A $\alpha$-amilase promove a conversão do amido em açúcar, que é utilizado para o crescimento do eixo embrionário (Arteca, 1996).

Embora o tratamento com $\mathrm{AG}_{3}$ e $\mathrm{ABA}$ tenha promovido maior atividade da $\alpha$-amilase somente no sétimo dia após a germinação trabalhos utilizando técnicas moleculares comprovaram que as giberelinas aumentam a transcrição de genes que codificam a $\alpha$-amilase, por meio do maior teor de mRNA dessa enzima observada (Higgins et al., 1976; Chandler et al., 1984). O resultado obtido com o tratamento com ABA difere do encontrado por Nolan e Ho (1988) que verificaram redução na atividade de $\alpha$-amilase em sementes de aveia tratadas com ABA. Ny e Bradford
(1992) propuseram que baixos níveis de ABA podem apenas diminuir a atividade da enzima, enquanto que altas concentrações poderiam inibir completamente a sua atividade.

\section{CONCLUSÕES}

De maneira geral, os fitorreguladores não afetam a viabilidade das sementes de alface cv. Grand Rapids; porém, promovem aumento da atividade total da enzima $\alpha$-amilase em sementes e plântulas de alface cv. Grand Rapids;

Sementes de alface cv. Grand Rapdis tratadas com espermina apresentam pior desempenho no vigor, menor emergência e índice de velocidade de emergência de plântulas, maior lixiviação de íons (condutividade elétrica) 
e inibição do crescimento das raízes.

\section{AGRADECIMENTOS}

À Fundação de Amparo e Pesquisa do Estado do Rio Grande do Sul (FAPERGS), pelo apoio financeiro para execução do projeto.

\section{REFERÊNCIAS}

AOSA - ASSOCIATION OF OFFICIAL SEED ANALYSTIS (Ed.) Seed vigour testing handbook. Contrib. n.32 to the Handbook on seed testing. 1983. 88p.

ARAGÃO, C.A.; LIMA, M.W.P.; MORAIS, O.M.; ONO, E.O.; BOARO, C.S.F.; RODRIGUES, J.D.; NAKAGAWA, J.; CAVARIANI, C. Fitorreguladores na germinação de sementes e no vigor de plântulas de milho super doce. Revista Brasileira de Sementes, v.23, n.1, p.62-67, 2001.

ARAGÃO, C.A.; DANTAS, B.F.; ALVES, E.; CATANEO, A.C.; CAVARIANI, C.; NAKAGAWA, J. Atividade amilolítica e qualidade fisiológica de sementes armazenadas de milho super doce tratadas com ácido giberélico. Revista Brasileira de Sementes, v.25, n.1, p.43-48, 2003.

ARTECA, R.D. Plant growth substances: principles and applications. New York: Chapman e Hall, 1996. 332p.

BORGES, E.E.L.; NOVAIS, A.B.; BORGES, R.C.G. Controle da germinação de sementes de angico vermelho (Piptadenia peregrina) pelo ácido abscísico. Revista Brasileira de Sementes, v.12, n.2, p.9-16. 1990.

BRASIL. Ministério da Agricultura e Reforma Agrária. Secretaria Nacional de Defesa Agropecuária. Departamento Nacional de Produção Vegetal. Coordenação de Laboratório Vegetal. Regras para análise de sementes. Brasília, DF, 2009. 395p.

CARNEIRO, L.M.T.A.; RODRIGUES, T.J.D.; FERRAUDO, A.S.; PERECIN, D. Ácido abscísico e giberélico na germinação de sementes de alfafa (medicago sativa 1.). Revista Brasileira de Sementes, v.23, n.2, p.177-185. 2001.

CHANDLER, P.M.; ZWAR, J.A.; JACOBSEN, J.V.; HIGGINS, T.J.V.; INGLIS, A.S. The effect of gibberellic acid and abcisic acid on a-amilase mRNA levels in barley aleurone layers. Studies usind na a-amilase cDNA clone. Plant Molecular Biology, v.3, n.6, p.407-418, 1984.

GALSTON, A.W.; KAUR-SAWHNEY, R. Polyamines as endogenous growth regulators. In: DAVIES, P.J. (Ed.). Plant hormones physiology, biochemistry and molecular biology. Dordrecht: Kluwer Academic, p.280-295, 1995.

GARCIARRUBIO, A.; LEGARIA, J.P.; COVARRUBIOS, A.A. Abscisic acid inhibits germination the availability of energy and nutrients. Planta, v.203, n.2. p.182-187, 1997.

GEMECI, M.; ÜNAL, D.; AZERI, F.N.; TAN, K. Correlation between polyamines and growth regulators. JFS, Copyright, E.U.F.F. (Turkey), v.29, p.13-23, 2006.

HIGGINS, T.J.V.; ZWAR, J.A.; JACOBSEN, J.V. Gibberellic acid enhances the level of translatable mRNA for a-amilase in barley aleurone layers. Nature, v.260, p.166-169, 1976.

KOETJE, D.S.; KONONOWICZ, H.; HODGES, T.K. Polyamine metabolism associated with growth and embryogenic potencial of rice. Journal of Plant Physiology, v.141, p.215-220, 1993.

MATILLA, A.J. Polyamines and seed germination. Seed Science Research, v.6, p.81-93, 1996.

MENEZES, N.L.; ESPINDOLA, M.C.G.; PASQUALLI, L.L.; SANTO, C.M.R.; FRAZIN, S.M. Associação de tratamentos pré-germinativos em sementes de alface. Revista da FZVA, v.13, n.1, p.1-11. 2006.

MORAES, D.M.; LOPES, N.F. Germinação e vigor de sementes de coentro (Coriandrum sativum 1.) submetidas a reguladores de crescimento vegetal. Revista Brasileira de Sementes, v.20, n.1, p.93-99. 1998

MULKEY, T.J.; EVANS, M.L.; KUSMAROFF, K.M. The Kinetics of abscisic acid action on root growth and gravitropism. Planta, v.157, p.150-7. 1983.

NI, B.R.; BRADFORD, K.J. Quantitative models characterizing seed germination responses to abscísico acid and osmoticum. Plant Physiology, v.98, p.1057-1068. 1992.

NOLAN, R.C.; HO, T.D. Hormonal regulation of $\alpha$-amylase expression in barley aleurone layers. Plant Physiology., v.88, p.588 -93, 1988.

SALISBURY, F.B.; ROSS, C.W. Plant Physiology. Belmont: Wadsworth, 1991. 682p.

SINSKA, I.; LEWANDOWSKA, U. Polyamines and ethylene in the removal of embryonal dormancy in apple seeds. Physiologia Plantarum, v.81, p.59-64, 1991.

TAIZ, L.; ZEIGER, E. Fisiologia vegetal. 3.ed. Porto Alegre: Artmed, 2004. 719p.

TIMM, F.C.; GARCIA, S.M.; SILVA, V.N.; DODE, J.; BERVALD, C.M.P.; MORAES, D.M. Qualidade fisiológica 
de sementes de lotes de Avena strigosa Sch. submetidas ao ácido giberélico. In: REUNIÃO DA COMISSÃO BRASILEIRA DE PESQUISA DE AVEIA, 18., 2008, Pelotas. Anais... Pelotas: UFPEL, 2008. p.311-314.

ZHAO, M-G.; LIU, R-J.; CHEN, L.; TIAN, Q-Y.; AHANG, $\mathrm{W}-\mathrm{H}$. Glucose-induced inhibition of seed germination in
Lótus japonicus is alleviated by nitric oxide and spermine. Journal of Plant Physiology, v.166, p.213-218. 2009.

ZEEVART, J.A.D.; CREELMAN, R.A. Metabolism and physiology of abscisic acid. Annual Review of Plant Physiolology, v.39, p.439-73, 1988. 